Article

\title{
Factors Related to Malondialdehyde (MDA) Levels in Metal Casting Industry Workers
}

\author{
Ari Suwondo ${ }^{*}$, Ahmad Mohan ${ }^{1}$, Melyana Nurul Widyawati2 ${ }^{*}$, Mardiyono ${ }^{2}$ \\ 1 Faculty of Public Health, Diponegoro University, Semarang, Central Java (50275), Indonesia \\ 2 Health Polytechnic Ministry of Health Semarang, Central Java (50268), Indonesia \\ * Correspondence: arisuwondo57@gmail.com \& melyana_nurul@poltekkes-smg.ac.id
}

\begin{abstract}
MDA, as a sign of oxidative stress, was increasing as a factor that changes the toxicity of responses in the workplace and causes male infertility etiology. This study aims to measure the MDA levels of workers in the casting industry metal. This type of research was analytical explanatory research with a cross-sectional design. This study's variables include the variables taken are MDA levels while the independent variables were age, years of service, type of work, IMT, marital status, and smoking habits. A saturated sampling technique took the research sample of 34 workers. Data analysis used univariate and bivariate methods. The results determined that respondents had MDA hormone levels below the average of 24 or $70.6 \%$, while respondents who had MDA levels above an average of 10 or $29.4 \%$. MDA levels relating to the length of work and marital status, while the type of work, IMT, and smoking habits are not associated with MDA levels in metal casting industry workers in the CV. Bonjor Jaya Klaten.
\end{abstract}

Keywords: expose, age, MDA, Metal Casting

Key Contribution: The length of time worked and the marital status are related to the MDA level of workers in the foundry industry.

\section{Introduction}

Malondialdehyde (MDA), as a sign of oxidative stress, was increasingly recognized as a possible mechanism for the toxicity of various chemical exposures in the workplace and the etiology of male infertility. The testes as a place for spermatogenesis are very susceptible to oxidation by free radicals. The testes will increase membrane fluidity, impaired membrane integrity, and in-activate membrane binding with enzymes and receptors due to lipid membrane peroxidation reactions. This case will lead to an increase in cell damage, including spermatozoa [1],[2]. Previous studies only examined workers in the casting and printing section and Pb's impact on the blood that exceeded the threshold. The results of prior research on workers at CV. Bonjor Jaya Klaten found that the casting and printing parts and $\mathrm{Pb}$ levels had exceeded the Threshold Value (NAV) set by the Regulation of the Minister of Manpower and Transmigration Number PER.13/MEN/X/2011, which was $0.05 \mathrm{mg} / \mathrm{Nm}^{3}$. The average $\mathrm{Pb}$ level in the blood at the casting, printing, and finishing sections had exceeded the Center for Disease Control and Prevention (CDC) limit, $10 \mu \mathrm{g} / \mathrm{dl}$ [3].

$\mathrm{Pb}$ also will damage the antioxidant enzymes like superoxide dismutase (SOD), Catalase (CAT), and Glutathione Peroxidase (GPx), which resulted in the formation of free radicals in the form of Reactive Oxygen Species (ROS) are not controlled. An imbalance between many free radicals and antioxidants causes oxidative stress to occur, associated with cell membranes, DNA, RNA, and damage to other cell organelles [4]. The level of damage due to oxidative stress can be measured by Malondialdehyde (MDA). Malondialdehyde (MDA) was a major aldehyde derived from the peroxidation of reactive three-carbon lipids in cell membranes and forming complex bonds with other elements in the network. The higher the oxidative stress in the body's cells has the same impact as the increasing MDA [5],[6]. 
The preliminary study results show signs of an increase in MDA in workers, namely excessive emotions in workers both in doing their work and in the family environment. The impacts of $\mathrm{Pb}$ decreased the level of health [7]. An increase in MDA characterized these workers; efforts must be made to counteract free radicals in the form that comes from lead them. Workers' personal efforts to do that were by eating foods that contain vitamin A, C, and E, such as nuts and vegetables that contain elements of mineral Zink, Fe, and Selenium. This food can stimulate antioxidant production enzymatic like SOD, Catalase, and glutathione peroxidase to reduce the impact lead in the body, causing oxidative stress and PPE during work must always be considered [6], [8].

Factors that are thought to be related to workers' MDA levels as found in previous research, include age [9], years of service, type of work, IMT [10], marital status and smoking habits [11]. Based on the previous study, it was found that there were signs of an increasing level of MDA from the results of interviews with workers, which became the reason for the researchers to conduct this research. This study aimed to measure workers' MDA levels and determine the relationship between individual characteristics factors and MDA levels in metal casting industry workers in the CV. Bonjor Jaya Klaten

\section{Results}

2.1 The levels of MDA

Work casting metal was a job that has potential high hazards. Potential hazards can come from the work process or work environment, and Individual characteristics influence the severity of the exposure. Workers in the foundry industry are susceptible to exposure to heavy metals such as $\mathrm{Cd}$ and $\mathrm{Pb}$, affecting the hormones testosterone and MDA in the body. Research carried out in $\mathrm{CV}$ fortification Jaya Klaten on in October 2019 by the sheer number of samples and 34 workers casting metal. The results of the research and analysis bivariate note that of the six variables, independent and variable dependent, no correlation was significant between variable dependent and variable independent. This study analyzed the relationship between ages, years of work, type of work, IMT, marital status, and smoking habits with MDA levels in metal casting workers. The examination MDA levels in workers in Industry Foundry Metal CV. Bonjor Jaya Klaten can be seen in the following table 1.

Table 1. The levels of MDA in Full Metal Casting Industry

\begin{tabular}{rcc}
\hline MDA levels & \multicolumn{2}{c}{ Total } \\
\cline { 2 - 3 } & $\mathrm{N}$ & $\%$ \\
\hline Below Average $(\leq 3534.16)$ & 24 & 70.6 \\
Above Average $(>3534.16)$ & 10 & 29.4 \\
Total & 34 & 100.0 \\
\hline
\end{tabular}

The results of the examination of 34 respondents in CV. Bonjor Jaya Klaten showed that the MDA levels were below the average of 24 workers $(70.6 \%)$ while the MDA levels were above the average of 10 workers (29.4\%).

2.2 The Relationship Factors and MDA Levels in Worker

To determine the relationship between the independent variable and the dependent variable in the form of testosterone hormone levels, it can be seen in the Table 2 . 
Table 2. The Relationship between Individual Factors and MDA Levels in Worker

\begin{tabular}{|c|c|c|c|c|c|c|c|}
\hline \multirow{3}{*}{ Variable } & \multicolumn{4}{|c|}{ MDA levels } & \multirow{2}{*}{\multicolumn{2}{|c|}{ Total }} & \multirow{3}{*}{$\mathrm{P}$} \\
\hline & \multicolumn{2}{|c|}{ Below average } & \multicolumn{2}{|c|}{ Above average } & & & \\
\hline & $\mathrm{N}$ & $\%$ & $\mathrm{~N}$ & $\%$ & $\mathrm{~N}$ & $\%$ & \\
\hline \multicolumn{8}{|l|}{ Age } \\
\hline$\leq 30$ years & 10 & 83.3 & 2 & 16.6 & 12 & 100 & \\
\hline$>30$ years & 14 & 63.6 & 8 & 36.4 & 22 & 100 & 0.432 \\
\hline Total & 24 & 70.6 & 10 & 29.4 & 34 & 100 & \\
\hline \multicolumn{8}{|l|}{$\mathrm{RP}=1.31095 \% \mathrm{CI}=0.874-1.963$} \\
\hline \multicolumn{8}{|l|}{ Years of expose } \\
\hline$\leq 5$ years & 13 & 92.9 & 1 & 7,1 & 12 & 100 & \\
\hline 5 years & 11 & 55 & 9 & 45 & 22 & 100 & 0.024 \\
\hline Total & 24 & 70.6 & 10 & 29.4 & 34 & 100 & \\
\hline \multicolumn{8}{|l|}{$\mathrm{RP}=0.15995 \% \mathrm{CI}=0.023-1.115$} \\
\hline \multicolumn{8}{|l|}{ Type of work } \\
\hline Finishing & 9 & 64.3 & 5 & 35.7 & 14 & 100 & \\
\hline Casting & 15 & 75 & 5 & 25 & 20 & 100 & 0.704 \\
\hline Total & 24 & 70.6 & 10 & 29.4 & 34 & 100 & \\
\hline \multicolumn{8}{|l|}{$\mathrm{RP}=1.42995 \% \mathrm{CI}=0.508-4.019$} \\
\hline \multicolumn{8}{|l|}{ IMT } \\
\hline Normal & 17 & 70.8 & 7 & 29.2 & 24 & 100 & 1,000 \\
\hline Abnormal & 7 & 70 & 3 & 30 & 10 & 100 & \\
\hline Total & 24 & 70.6 & 10 & 29.4 & 34 & 100 & \\
\hline \multicolumn{8}{|l|}{$\mathrm{RP}=0.97295 \% \mathrm{CI}=0.313-3.021$} \\
\hline \multicolumn{8}{|l|}{ Marital status } \\
\hline Not yet & 9 & 100 & 0 & 0 & 9 & 100 & 0.034 \\
\hline Married & 15 & 60 & 10 & 40 & 25 & 100 & \\
\hline Total & 24 & 70.6 & 10 & 29.4 & 34 & 100 & \\
\hline \multicolumn{8}{|l|}{$\mathrm{RP}=1,66795 \% \mathrm{CI}=1,210-2,295$} \\
\hline \multicolumn{8}{|l|}{ Smoking } \\
\hline Do not smoke & 8 & 61.5 & 5 & 38.5 & 13 & 100 & 0.451 \\
\hline Smoke & 16 & 76.2 & 5 & 23.8 & 21 & 100 & \\
\hline Total & 24 & 70.6 & 10 & 29.4 & 34 & 100.0 & \\
\hline $\mathrm{RP}=1.61595 \% \mathrm{CI}=0.577-4.519$ & & & & & & & \\
\hline
\end{tabular}

Table 2 shows the relationship between the independent variables, namely age, years of work, type of work, IMT, marital status, and smoking habits with MDA levels at CV. Bonjor Jaya Klaten. The prevalence of respondents whose MDA levels were below the average was $83.3 \%$ or 10 respondents under 30 years old were greater than those of more than 30 years old, namely $63.6 \%$ or 14 respondentsThe results of the analysis Chi-square test were used to analyze the relationship between age and MDA levels in the CV. Bonjor Jaya Klaten. The result was obtained $\mathrm{p}=0.432$. The alternative hypothesis ( $\mathrm{Ha}$ ) in this study was rejected, which means that there was no significant relationship between the age of the respondent and the MDA level of the employees of CV Bonjor Jaya Klaten. The prevalence of respondents whose MDA levels were below the average was $92.9 \%$ or 
13 respondents with a service period of fewer than 5 years was greater than respondents who had a work period of more than 5 years, namely $55 \%$ or 11 respondents. The analysis resulted in using the Chi-square test to analyze the relationship between tenure and MDA levels in the CV. Bonjor Jaya Klaten obtained $p=0.024$. Base on the result, the alternative hypothesis (Ha) in this study was accepted, which means a significant relationship between tenure and MDA levels in CV workers. Bonjor Jaya Klaten. The results of $\mathrm{RP}=0.159$ with a confidence interval $(\mathrm{CI})$ of $95 \%$ (0.023 - 1.15), so from these results, it can be said that tenure was not a high-risk factor for low MDA levels.

The prevalence of respondents whose MDA levels were below the average was $75 \%$, or 15 respondents who had a casting work were greater than respondents who had a finishing work, namely $64.3 \%$ or 9 respondents. The analysis results using the Chi-square test to analyze the relationship between age and MDA levels in the CV. Bonjor Jaya Klaten obtained $p=0.704$. The alternative hypothesis (Ha) in this study was rejected, which means no significant relationship between the type of work and the MDA level.

The prevalence of respondents with MDA levels below the average was $70.8 \%$, or 17 respondents who had normal IMT were greater than respondents who had abnormal IMT, namely $70 \%$ or 7 respondents. The analysis results used the Chi-square test to analyze the relationship between IMT and MDA levels in the CV. Bonjor Jaya Klaten obtained $p=1,000$. The alternative hypothesis (Ha) in this study was rejected, which means no significant relationship between IMT and MDA levels in the CV. Bonjor Jaya Klaten.

The prevalence of respondents with MDA levels below the average was $100 \%$ or 9 respondents with unmarried status were smaller than those married, namely $60 \%$ or 15 respondents. The analysis results used the Chi-square test to analyze the relationship between marital status and MDA levels in the CV. Bonjor Jaya Klaten obtained $p=0.034$. The alternative hypothesis (Ha) in this study was accepted, which means a significant relationship between marital status and MDA levels of respondent workers at $\mathrm{CV}$. Bonjor Jaya Klaten. The results of $\mathrm{RP}=1.667$ with a confidence interval (CI) of $95 \%$ (1.210 - 2.295), so from these results, it can be said that unmarried respondents have a risk of 1.667 times having MDA levels below the average.

The prevalence of respondents whose MDA levels were above the average was $76.2 \%$, or 16 respondents who had a smoking habit were greater than those who had a non-smoking habit, namely $61.5 \%$ or 8 respondents. The analysis results with the Chi-square test to analyze the relationship between smoking habits and MDA levels in the CV. Bonjor Jaya Klaten obtained $p=0.451$. The alternative hypothesis $(\mathrm{Ha})$ in this study was rejected, which means no significant relationship between smoking habits and MDA levels in CV workers. Bonjor Jaya Klaten.

\section{Discussion}

This study's findings indicate that the longer a person works in a work environment, especially in an unsupportive work environment, the more oxidative stress conditions will increase. This increase in oxidative stress also triggers an increase in a person's MDA levels. Therefore, special handling was needed for workers who have a working period of more than 5 years to create a work atmosphere that can eliminate stress. The study was in line with [12] research, comparing the levels of MDA on workers smelter nickel with worker administrative. It was found that MDA levels in nickel smelter workers were higher than administrative workers. Then the correlation test was carried out. It was found that there was a positive correlation with the length of service with the addition of MDA levels in nickel smelter workers $(\mathrm{p}<0.001)$. In contrast, there was no relationship between years of service and MDA levels $(\mathrm{p}=0.085)$. The smelter nickel workers showed a trend increase in the sharp levels of MDA after 5-9 years of past work and then began to decline.

Prolonged time of exposure to nickel, nickel can accumulate in the body of a human and be continually able to improve the process of oxidative acid fat was unsaturated double in the membranes of cells and exacerbate the level of peroxide lipids. MDA was the most representative indicator of the terminal metabolites of peroxide in lipids. It reflects the content of radical free, produced in the body, and can predict the intensity and rate of reaction peroxide lipids and oxidative damaged cells. The results showed that of the 14 respondents who had the type of work in the 
finishing section, there were 14 respondents while those who had MDA levels above the average were 5 respondents ( $35.7 \%$ ) while those who were below the average were 9 respondents $(64,3 \%)$. For respondents with a casting section of 20 respondents, 5 respondents (25\%) had MDA levels above the average, and 15 respondents (75\%) had MDA levels below the average. As a percentage, these results show that the prevalence of respondents with more types of casting work has MDA levels below the average compared to respondents who have types of work in the finishing section.

The chi-square statistical analysis results obtained $\mathrm{p}=0.704$, indicating no significant relationship between the type of work and the MDA level of the CV. Bonjor Jaya Klaten. However, the respondents' prevalence has MDA levels below the average found in respondents who work in foundries. There was no relationship between the type of work and MDA levels in the CV. Bonjor Jaya Klaten shows that among the workers, both those who work in the foundry and finishing departments have MDA levels that are not much different. In this case, the type of work cannot increase or decrease MDA levels because both types of work can create oxidative stress and be reduced by these workers

The results showed 24 respondents whose IMT was normal, while 10 respondents had abnormal IMT. Of the 10 respondents who had abnormal IMT, there were 3 respondents (30\%) with MDA levels above the average and 7 respondents (70\%) with MDA levels below the average. As a percentage, these results show that the prevalence of respondents with abnormal IMT was more likely to have MDA levels below the average than respondents with normal IMT. The chi-square statistical analysis results showed that the value of $\mathrm{p}=1,000$ indicated no significant relationship between IMT and MDA levels in the CV. Bonjor Jaya Klaten. However, the prevalence of respondents who had MDA levels above the average was mostly found in respondents with normal IMT. The absence of a significant relationship between IMT and MDA levels in this study was different from the findings of [13]. There was a relationship between excess IMT and levels of Malondialdehyde (MDA). There was an increase in MDA levels in the obese group. The increase in MDA plasma as an indicator of the stress of oxidation caused by the increase in peroxidation of lipids induced by the radical free due to an increase in people with severe weight excess.

Lipid peroxidase was a process that produces free radicals that take place in every cell membrane structure. A study determined that obesity was associated with lipid peroxidase. The mechanism further IMT excess can freely increase the peroxidation of lipids in a progressive and accumulation of cell death caused by the pressure of the body's mass, which was excellent. This cell death was caused by the release of cytokines, such as TNF- $\alpha$, which can produce ROS from the tissues when lipid peroxidase occurs [14][15].

The results showed that 9 respondents were unmarried, while 25 respondents were married. Of the 25 married respondents, 10 respondents (40\%) with MDA levels above the average, and 15 respondents $(60 \%)$ with MDA levels below the average. All of the unmarried respondents had MDA levels below average. These results show that the prevalence of respondents with the status of being married was more likely to have MDA levels above the average than those who are not married. The chi-square statistical analysis results obtained $p=0.034$, indicating a significant relationship between marital status and MDA levels in the CV. Bonjor Jaya Klaten, with the prevalence of respondents who have MDA levels above the average, tends to occur in married respondents. These findings indicate that marital status can increase MDA levels. In this case, married men have a higher prevalence than unmarried men on MDA levels because they tend to have a big life burden, problems, and responsibilities that lead to stress, which impacts increasing MDA levels.

In the research results, it can be seen that 13 respondents do not smoke and 21 respondents who smoke; of the 21 respondents who smoked, 16 respondents (76.2\%) with MDA levels below the average, and 5 respondents $(23.8 \%)$ with above-average MDA levels. Among non-smoking respondents, there were 8 respondents (61.5\%) with MDA levels below the average and 5 respondents $(38.5 \%)$ with MDA levels above the average. As a percentage, these results show that respondents with smoking habits are more likely to have MDA levels below the average than those who do not smoke. The chi-square statistical analysis results obtained $\mathrm{p}=0.451$, indicating no significant relationship between smoking and MDA levels in the CV. Bonjor Jaya Klaten. However, 
the prevalence of respondents who have MDA levels below the average tends to occur in respondents with a smoking habit. This study found no significant relationship between smoking with MDA levels in contrast to the results of research [16] found no difference in levels of MDA significantly between smokers and non-smokers. Smoking was one habit that increases free radicals, and the content of nitrogen oxides from cigarette smoke are strong oxidizers that cause lipid peroxides and produce MDA. Research by [17] showed that MDA increases are significant in between workers smokers compared with workers of non- smokers. Pesticides, such as smoking, can induce stress oxidative to produce radical free and alter the enzyme antioxidant activity collect radical free. Biomarkers of stress oxidative MDA was significantly higher in smokers worker pesticide and nonsmokers compared to control them and the worker smokers than workers of non- smokers. So, exposure to working them to pesticides and smoke are considered having the effect of the increase in MDA extra in between the workers of smokers.

\section{Conclusions}

Based on the research and discussion results in the previous chapter, the researcher can conclude that (1) the respondents who had MDA levels below the average were 24 or $70.6 \%$, while the respondents who had MDA levels above the average were 10 or $29,4 \%$. (2) There was a relationship between the length of service and the marital status of the MDA. In contrast, age, type of job, the status of nutrition, and the habit of smoking was not associated with levels of MDA on workers of industrial foundries late metal CV. Bonjor Jaya Klaten. Therefore, the research suggests that companies should routinely carry out medical check-ups for all workers to determine workers' conditions and make reasonable anticipations in protecting workers' health. Workers should have a healthy life like regular exercise and reduce food causes obesity. The next researcher should add independent variables that are thought to influence testosterone levels, such as lead levels, so that the research results can later determine the impact of the work environment on MDA levels and testosterone levels.

\section{Materials and Methods}

Based on the goal, research was included in the research explanatory research, which analyzed the relationship variables research to test the formulated hypothesis. The design of the research used was the method of survey analytic with an approach cross-sectional [18]. The population in this study were all workers at CV. Bonjor Jaya Klaten as many as 34 people. The technique of taking samples used in the research was the sampling technique (total sampling) so that all members of the population that was as much as 34 workers will be used as a sample study. There were two types of miscellany bell, which was the variable Independent and variable dependent. The study variables are age, marital status, smoking habits, IMT, type of work, and a job, while that becomes a variable dependent was the level of MDA. The age variable that respondents counted in the year since birth until the research was carried out using a ratio scale. Status of nutrition shows the nutrition response status by using the formula BMI was weight/height. The working period was the time that was counted in the year that has used the respondents to work in welding differentiated into two $<5$ years and $>5$ years. The respondents did type work employees were part of casting and finishing. Marital status was a status that indicates whether the respondent was married or not. Smoking habits, namely the habits of respondents in consuming cigarettes, was differentiated into smokers and non-smokers.

Variable malondialdehyde (MDA) levels were the end product of lipid peroxidation used as a biological biomarker of lipid peroxidation to assess oxidative stress. MDA levels were measured on a nominal scale that was normal if the plasma and serum TBARS should be $<1.5$ and $<2.0 \mathrm{ng} / \mathrm{dl}$, and abnormal TBARS plasma and serum should be $>1.5$ and $>2.0 \mathrm{ng} / \mathrm{dl}$. The data sources in this study are primary data and secondary data. Primary data was a data source that directly provides data to data collectors. Primary data in this study were obtained by distributing questionnaires. Secondary data sources do not directly provide data to data collectors, for example, through other people or documents. Data secondary in the study was derived from the laboratory results for lead $(\mathrm{Pb})$ levels 
in the blood, MDA conducted at the Laboratory of the Biotechnology University of Gajah Mada in Yogyakarta.

Blood samples were taken using blood sampling equipment in a syringe, $70 \%$ alcohol, cotton, tube samples, cold boxes, label paper. Capturing a blood sample have done by officers laboratory trained as much as 5-10 cc and sent to the laboratory using the Cool chain. The solution of EDTA was used to prevent the occurrence of damage to the sample. Then, Blood lead levels were analyzed using a spectrophotometer with the AAS (Atomic Absorbance Spectrometer) method. The study's MDA hormone levels were measured by the enzyme-linked immunosorbent assay (ELISA) method conducted at the Biotechnology Laboratory of Gajah Mada University, Yogyakarta. Data analysis consisted of univariate analysis and bivariate analysis. Analysis Univariate analysis was performed on each variable of the study. This analysis was carried out on each variable, namely the variable age, IMT, years of service, type of work, marital status, smoking habits, and MDA levels. Bivariate analysis was an analysis conducted on two variables that are thought to be related or correlated.

Author Contributions: Conceptualization, A.S. and M.N.W.; methodology, A.S.; software, A.M.; validation, A.S., A.M. and M.M.; formal analysis, A.S.; investigation, M.N.W.; resources, A.M.; data curation, M.M.; writing-original draft preparation, A.S.; writing-review and editing, A.S, M.N.W; supervision, A.S.; project administration, M.N.W.; funding acquisition, A.S. All authors have read and agreed to the published version of the manuscript.

Funding: This research was funded and supported through an internal grant from the Public Health Faculty of Diponegoro University.

Acknowledgments: We thank our colleagues from Health Polytechnic Ministry of Health Semarang and colleagues from the Department of Occupational Safety and Health, who provided insight and expertise that greatly assisted this research.

Conflicts of Interest: The authors declare no conflict of interest.

All subjects gave their informed consent for inclusion before they participated in the study. The study was conducted in accordance with Ethical Clearance No: 264/EC/FKM/2017

\section{References}

[1] Li, R., Luo, X., Li, L., Peng, Q., Yang, Y., Zhao, L., ... \& Hou, Z.The Protective Effects of Melatonin Against Oxidative Stress and Inflammation Induced by Acute Cadmium Exposure in Mice Testis. Biol. Trace Elem. Res., 2016, 170(1), 152-164. doi: 10.1007/s12011-015-0449-6.

[2] Guerriero, G., Trocchia, S., Abdel-Gawad, F. K., \& Ciarcia, G. Roles of reactive oxygen species in the spermatogenesis regulation. Frontiers in Endocrinology. 2014, 5, 56. doi: 10.3389/fendo.2014.00056.

[3] Lestari, V. D., Setiani, O., \& Dewanti, N. A. Y. Differences in the levels of Timbale (Pb) in the blood based on the type of work of metal casting industry workers at CV. Bonjor Jaya, Klaten," J. Kesehat. Masy., vol. 3, no. 3, pp. 819-831, 2016.

[4] Weydert, C. J., \& Cullen, J. J. Measurement of superoxide dismutase, catalase and glutathione peroxidase in cultured cells and tissue, Nat. Protoc., 2010, 5(1), 51-66. doi: 10.1038/nprot.2009.197.

[5] Rahal, A., Kumar, A., Singh, V., Yadav, B., Tiwari, R., Chakraborty, S., \& Dhama, K. Oxidative stress, prooxidants, and antioxidants: The interplay," BioMed Research International. 2014, doi: $10.1155 / 2014 / 761264$.

[6] Pirinccioglu, A. G., Gökalp, D., Pirinccioglu, M., Kizil, G., \& Kizil, M. Malondialdehyde (MDA) and protein carbonyl (PCO) levels as biomarkers of oxidative stress in subjects with familial hypercholesterolemia, Clin. Biochem., 2010, 43(15), 1220-1224. doi: 10.1016/j.clinbiochem.2010.07.022.

[7] Sanders, T., Liu, Y., Buchner, V., \& Tchounwou, P. B. Neurotoxic effects and biomarkers of lead 
exposure: A review, Reviews on Environmental Health. 2009, 24(1), 15. doi: 10.1515/REVEH.2009.24.1.15.

[8] Grotto, D., Maria, L. S., Valentini, J., Paniz, C., Schmitt, G., Garcia, S. C., ... \& Farina, M. Importance of the lipid peroxidation biomarkers and methodological aspects for malondialdehyde quantification, Quimica Nova. 2009, 32(1), 169-174. doi: 10.1590/S0100-40422009000100032.

[9] Gupta, R. K., Patel, A. K., Kumari, R., Chugh, S., Shrivastav, C., Mehra, S., \& Sharma, A. N. Interactions between oxidative stress, lipid profile and antioxidants in breast cancer: A case control study, Asian Pacific J. Cancer Prev, 2012, 13(12), 6295-8. doi: 10.7314/APJCP.2012.13.12.6295.

[10] Del Rio, D., Stewart, A. J., \& Pellegrini, N. A review of recent studies on malondialdehyde as toxic molecule and biological marker of oxidative stress, Nutrition, Metabolism and Cardiovascular Diseases. 2005, 15(4), 316-328. doi: 10.1016/j.numecd.2005.05.003.

[11] Trinick, T. R., Feneley, M. R., Welford, H., \& Carruthers, M. International web survey shows high prevalence of symptomatic testosterone deficiency in men, The aging male, 2011, 14(1), 10-15. doi: 10.3109/13685538.2010.511325.

[12] Cheng, Z., Cheng, N., Shi, D., Ren, X., Gan, T., Bai, Y., \& Yang, K. The relationship between Nkx2.1 and DNA oxidative damage repair in nickel smelting workers: Jinchang cohort study, Int. J. Environ. Res. Public Health, 2019, 16(1), 120. doi: 10.3390/ijerph16010120.

[13] Yang, R. L., Shi, Y. H., Hao, G., Li, W., \& Le, G. W. Increasing oxidative stress with progressive hyperlipidemia in human: Relation between malondialdehyde and atherogenic index, J. Clin. Biochem. Nutr., 2008, 43(3), 154-158. doi: 10.3164/jcbn.2008044.

[14] Amirkhizi, F., Siassi, F., Minaie, S., Djalali, M., Rahimi, A., \& Chamari, M. Is obesity associated with increased plasma lipid peroxidation and oxidative stress in women?, ARYA Atheroscler., 2007. 2(4).

[15] Lima, S. C., Arrais, R. F., Almeida, M. G., Souza, Z. M., \& Pedrosa, L. F. Plasma lipid profile and lipid peroxidation in overweight or obese children and adolescents, J. Pediatr. (Rio. J)., 2004, 80(1), 23-28. doi: 10.2223/jped.1129.

[16] Kashinakunti, S. V., Kollur, P., Kallaganada, G. S., Rangappa, M., \& Ingin, J. B. Comparative study of serum MDA and vitamin C levels in non-smokers, chronic smokers and chronic smokers with acute myocardial infarction in men, J. Res. Med. Sci., 2011, 16(8), 993.

[17] Tagesson, C., Källberg, M., \& Wingren, G. Urinary malondialdehyde and 8-hydroxydeoxyguanosine as potential markers of oxidative stress in industrial art glass workers, Int. Arch. Occup. Environ. Health, 1996, 69(1), 5-13. doi: 10.1007/BF02630732.

[18] Schwartz, S. P., Adair, K. C., Bae, J., Rehder, K. J., Shanafelt, T. D., Profit, J., \& Sexton, J. B. Work-life balance behaviours cluster in work settings and relate to burnout and safety culture: A cross-sectional survey analysis," BMJ Qual. Saf., 2019, 28(2), 142-150. doi: 10.1136/bmjqs-2018-007933. 